\title{
Coated Capsule Dosage Form
}

National Cancer Institute

\section{Source}

National Cancer Institute. Coated Capsule Dosage Form. NCI Thesaurus. Code C42895.

A capsule that contains an additional outer layer over the capsule shell. 